дарственный аграрный университет - МСХА имени К.А. Тимирязева. Россия.

127550, г. Москва, ул. Тимирязевская, 49.

Тел.: (499) 976-04-80; e-mail: dulger@rgau-msha.ru.
Ключевъе слова: кошки; патология матки; железисто-кистозная гиперплазия эндометрия; пиометра; лечение.

\title{
INCIDENCE, RISK FACTORS, PHATHOPHISIOLOGY AND MODERN ASPECTS OF THERAPY OF FELINE PYOMETRA
}

Dyulger Georgy Petrovich, Doctor of Veterinarian Sciences, Head of the chair "Vet-erinary Medicine", RGAU-MSHA named after K.A. Timiryazev. Russia.

Sibileva Yuliya Gennadievna, Senior Veterinarian of the Laboratory of Physiology and Pathology of Reproduction of Small Animals, RGAU-MSHA named after K.A. Timirya-zev. Russia.

Yakovleva Maria Aleksandrovna, Senior Laboratory Assistant of the of the chair "Veterinary Medicine", RGAU-MSHA named after K.A. Timiryazev. Russia.

Dyulger Peter Georgievich, Candidate of Veterinarian Sciences, Senior Teacher of the chair "Veterinary Medicine", RGAUMSHA named after K.A. Timiryazev. Russia.

Sedletskaya Evgeniya Sergeevna, Candidate of Veterinarian Sciences, Senior Teacher of the chair "Veterinary Medicine", RGAU-MSHA named after K.A. Timiryazev. Russia.

Akchurina Irina Vladimirovna, Candidate of Veterinary Sciences, Associate Profes-sor of the chair "Veterinary Medicine", RGAU-MSHA named after K.A. Timiryazev. Russia.

Obukhova Maria Evgenievna, Candidate of Veterinary Sciences, Associate Professor of the chair "Veterinary Medicine", RGAU-MSHA named after K.A. Timiryazev. Russia.

Bychkov Vladislav Sergeevich, Candidate of Veterinar- ian Sciences, Teacher of the chair "Veterinary Medicine", RGAUMSHA named after K.A. Timiryazev. Russia.

Latynina Evgeniya Sergeevna, Assistant of the chair "Veterinary Medicine”, RGAU-MSHA named after K.A. Timiryazev. Russia.

Keywords: feline; uterine diseases; cystic endometrial hyperplasia; pyometra; treat-ment

The article provides an overview of the frequency of distribution of pyometra in cats. Risk factors, clinical manifestations and clinical forms of the disease are analyzed. Current methods of pyometra diagnostics and clinical and laboratory criteria for early detection of signs of sepsis (systemic inflammatory response) in cats with pyometra are considered. The methods of pyometra therapy are analyzed. It was emphasized that the most effective and safest method of treating any form of pyometra is a total ovariohisterectomy in combination with broad-spectrum antibiotics. Encouraging results in the treatment of an open uncompli-cated form of pyometers in cats were obtained using, along with antibiotics, preparations based on PgF2alfa and aglepristone.

\section{ВЛИЯНИЕ КОРОВ-МАТЕРЕЙ НА ФИЗИКО-ХИМИЧЕСКИЕ СВОЙСТВА МОЛОКА ДОЧЕРЕЙ}

\author{
ЕФИМОВА Любовь Валентиновна, Красноярский научно-исследовательский институт \\ животноводства - обособленное подразделение ФИЦ КНЦ СО РАН
}

ЗАЗНОБИНА Татьяна Вячеславовна, Красноярский научно-исследовательский институт животноводства - обособленное подразделение ФИЦ КНЦ СО РАН

ФРОЛОВА Ольга Анатольевна, Красноярский научно-исследовательский институт животноводства - обособленное подразделение ФИЦ КНЦ СО РАН

ОВЧАРЕНКО Андрей Станиславович, Красноярский научно-исследовательский институт животноводства - обособленное подразделение ФИЦ КНЦ СО РАН

ИВАНОВА Ольга Валерьевна, Красноярский научно-исследовательский институт животноводства - обособленное подразделение ФИЦ КНЦ СО РАН

Установлено влияние уровня продуктивности матерей на суточный удой и физико-химические свойства молока дочерей. Определены взаимосвязь и наследуемость признаков, а также сила влияния двух факторов (возраст коров-дочерей в лактациях и уровень удоя матерей) на компонентный состав и физические свойства молока коров-дочерей. Исследования, проведенные в АО «Арефъевское» Красноярского края на коровах красно-пестрой породы (43 пары «мать-дочъ»), показали, ито молоко коров-матерей по сравнению с молоком дочерей отличалось лучиими физико-химическими свойствами. Достоверным было превосходство дочерей над матерями по величине суточного удоя (вторая лактация) и лактозы (первая лактация) на 13,4 кг и 0,21 \% (Р>0,95 и Р>0,999). Выявлена положительная сильная связъ между содержанием сухого вещества и жира $(r=0,71$ и 0,79) в молоке матерей и дочерей. Установлено достоверное влияние матерей на содержание жира в молоке дочерей $\left(\eta^{2}=13,9 ;\right.$ P>0,99). Возраст (в лактациях) дочерей повлиял на суточный удой, содержание в молоке сухого вещества, сухого обезжиренного молочного остатка и температуру замерзания молока $\left(\eta^{2}=8,3-11,8 ; P>0,95-0,99\right)$.

Введение. Эффективность животноводства зависит от степени использования возможностей животных. На молочную продуктивность коров оказывают влияние внутренние и внешние факторы. Знание племенной ценности и продуктивности родителей коров является одним из аспектов, обеспечивающих успех селекционноплеменной работы [4]. Широкое использование 
в воспроизводстве высокопродуктивных коров и быков-производителей с высоким потенциалом продуктивности предков ускоряет темпы усовершенствования молочных стад. Это позволяет получать потомков с более высокими наследственными задатками, в наибольшей степени отвечающих требованиям современной экономики [6]. Большое значение имеют также вопросы повышения качества молока и получение безопасной для человека продукции [1].

Вопросы наследования высокой продуктивности молочных коров и улучшения физико-химических качеств молока интересуют как отечественных, так и зарубежных ученых. В ряде работ приведены данные изучения влияния коровматерей на уровень молочной продуктивности дочерей [2, 9, 13], физико-химические свойства молока [3], продуктивное долголетие [8], показатели здоровья дочерей $[5,7]$.

3.Е. Щербатый и П.В. Боднар [11] установили корреляцию между удоем матерей и удоем и количеством молочного жира дочерей, количеством молочного жира матерей и удоем и количеством молочного жира дочерей. При этом доля влияния удоя и содержания жира в молоке матерей на удой и содержание жира в молоке дочерей составила 0,24-31,31\%.

Д.С. Вильвер [4] в результате оценки коров первого отела по молочной продуктивности в зависимости от уровня удоя матерей за первую лактацию выявил влияние удоя матерей на аналогичный показатель дочерей и установил, что с увеличением удоя матерей у дочерей также повышается молочная продуктивность. Такую же тенденцию наблюдала С.В. Титова [8]. Кроме того, она установила силу влияния $\left(\eta^{2}\right)$ уровня удоя матерей по первой лактации на пожизненный удой и продолжительность продуктивного использования дочерей $\left(\eta^{2}=8,0-8,4 \%\right)$. Аналогичные результаты были получены Р.Р. Шайдуллиным и др. [10], которые в результате однофакторного дисперсионного анализа определили силу влияния уровня удоя матерей за первую лактацию на удой их дочерей $\left(\eta^{2}=4,0-12,6 \%\right)$. Вместе с тем D.P. Berry et al. [12] обнаружили, что у дочерей высокопродуктивных коров снижается удой и повышается содержание соматических клеток в молоке.

Новизна исследований заключается в том, что впервые в условиях Красноярского края изучена взаимосвязь и наследуемость физико-химических свойств молока у коров красно-пестрой породы и установлена сила влияния уровня продуктивности матерей на компонентный состав и физические свойства молока дочерей.

Целью исследований являлось изучение физико-химических свойств молока коров-матерей и их дочерей и установление взаимосвязи и наследуемости признаков.
Методика исследований. Научные исследования проводили в племенном репродукторе АО «Арефьевское» Канского района Красноярского края на коровах красно-пестрой породы. Было отобрано 43 пары коров «мать-дочь», которых распределили сначала по уровню удоя матерей за 305 дней последней законченной лактации $\leq 6000$ и >6000 кг молока, затем по возрасту последней законченной лактации дочерей - первая и вторая лактации. Коровы-матери были полновозрастные, коровы-дочери - в возрасте первой и второй законченной лактации.

Bсе животные находились в одинаковых условиях кормления и содержания (привязный способ с доением в молокопровод). Молоко для анализа брали утром во время проведения контрольной дойки. Его физико-химические показатели определяли в лаборатории по исследованию селекционного качества молока ОАО «Красноярскагроплем» на высокоскоростном инфракрасном анализаторе молока Bentley (США).

Биометрическую обработку полученных результатов проводили методами вариационной статистики с применением компьютерных программ «Пакет анализа для биометрической обработки зоотехнических данных» (Красноярский НИИЖ) и Microsoft Office Excel с расчетом статистических показателей и определением коэффициентов корреляции $(r)$ и наследуемости $\left(h^{2}\right)$. Коэффициент наследуемости вычисляли по формуле С. Райта путем удвоения коэффициента корреляции между показателями одного и того же признака матери и дочери. Оценку доли влияния различных факторов $\left(\eta^{2}\right)$ проводили с применением двухфакторного дисперсионного анализа. Достоверность разницы между средними значениями признаков в группах устанавливали по критерию Стьюдента, при этом разницу считали статистически значимой при $P>0,95$. Достоверность влияния факторов устанавливали по критерию Фишера $(F)$. Сила влияния фактора признавалась статистически значимой при следующих пороговых значениях трех уровней вероятности: $F_{0,95}=2,8 ; F_{0,99}=4,3 ; F_{0,999}=6,8$ для числа степеней свободы $3\left(v_{x}\right)$ и $39\left(v_{y}\right)$.

Результаты исследований. В результате изучения суточного удоя и физико-химических свойств молока коров установлено, что дочери, находящиеся в возрасте первой лактации, достоверно превосходили матерей (удой $\leq 6000$ кг) по содержанию лактозы на $0,21 \%(P>0,95)$ и уступали им по массовой доле жира на 0,48 \% $(P>0,95)$, табл. 1.

У дочерей в возрасте второй лактации по сравнению с матерями (удой $\leq 6000$ кг) суточный удой был выше на 13,4 кг ( $P>0,999)$, однако в их молоке содержалось меньше жира и сухого вещества на 0,77 и $0,90 \%(P>0,99 ; P>0,95)$ соответственно. В целом, молоко коров-матерей 


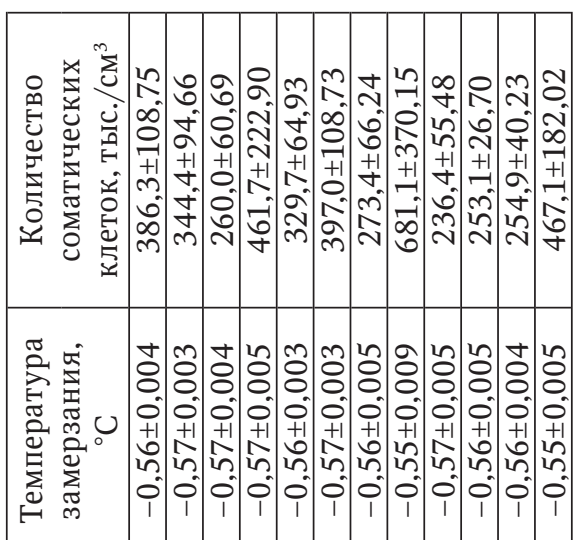

D
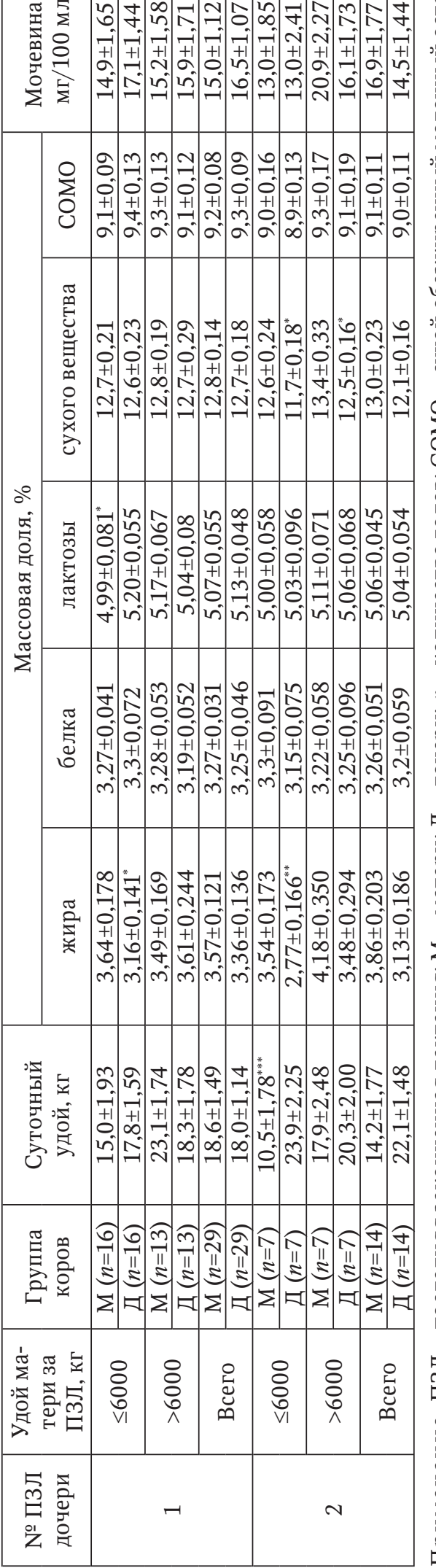

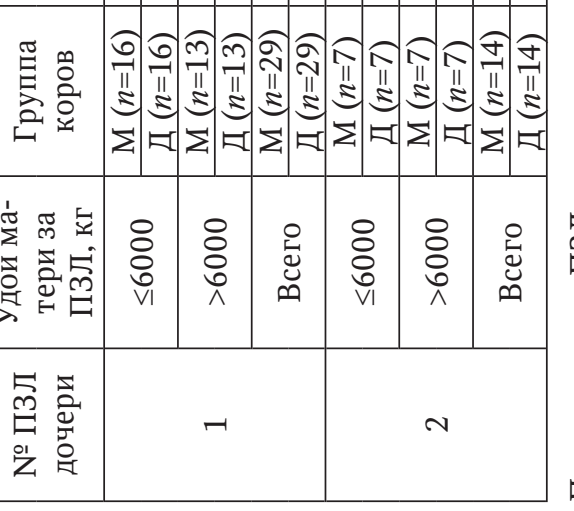

в сопоставлении с молоком дочерей отличалось лучшими физико-химическими показателями.

Следует отметить, что по физико-химическим свойствам молоко коров-матерей и их дочерей соответствовало требованиям ГОСТ 31449-2013, за исключением показателя количества соматических клеток, по которому было отмечено превышение нормы на 61,7-281,1 тыс./ см³ $^{3}$

В результате расчета коэффициентов корреляции (табл. 2) между физико-химическими свойствами молока матерей и дочерей выявлены слабые связи различной направленности $(r=-0,44 \ldots 0,30)$. Отрицательная корреляция средней силы обнаружена между содержанием сухого обезжиренного молочного остатка $(r=-0,54)$ в молоке матерей (удой $\leq 6000$ кг) и дочерей (2-я лактация); положительная сильная связь была между содержанием сухого вещества и жира $(r=0,71$ и 0,79$)$ в молоке матерей (удой $>6000$ кг) и дочерей (2-я лактация).

При расчете коэффициента наследуемости у высокопродуктивных коров (удой $>6000$ кг) отмечена тесная связь по отдельным признакам качественного состава молока. Так, высокие коэффициенты наследуемости установлены по содержанию в молоке жира ( $\left.h^{2}=0,87-0,99\right)$, сухого вещества $\left(h^{2}=0,63-0,99\right)$, COMO $\left(h^{2}=0,71\right)$ и по показателю температуры замерзания $\left(h^{2}=0,82\right)$. Полученные данные высокой наследуемости содержания жира в молоке согласуются с результатами, полученными 3.Е. Щербатым и П.В. Боднар [11].

Для определения силы влияния наследственных качеств на суточный удой и физико-химические свойства молока коров был проведен двухфакторный дисперсионный анализ, в котором градациями первого фактора был возраст дочерей в лактациях, а градациями второго фактора - уровень удоя матерей (табл. 3).

В результате анализа выявлено достоверное влияние возраста дочерей (в лактациях) на их суточный удой $\left(\eta^{2}=10,1 ; P>0,99\right)$, содержание сухого вещества в молоке $\left(\eta^{2}=8,3 ; P>0,95\right)$ и температуру замерзания $\left(\eta^{2}=11,8 ; P>0,99\right)$, а также влияние уровня удоя матерей на массовую долю жира в молоке дочерей $\left(\eta^{2}=13,9 ; P>0,99\right)$.

Заключение. В результате корреляционного и дисперсионного анализа выявлено, что уровень продуктивности матерей оказывает влияние на отдельные физико-химические свойства молока дочерей. Сильная положительная связь $(r=0,79)$ установлена между матерями и дочерями по содержанию жира в молоке. Высокая степень наследуемости выявлена у коров с уровнем продуктивности >6000 кг по содержанию в молоке жира, сухого вещества, СОМО и по температуре замерзания молока $\left(h^{2}=0,63-0,99\right)$.

Методом дисперсионного анализа подтвердилось влияние уровня продуктивности матерей 


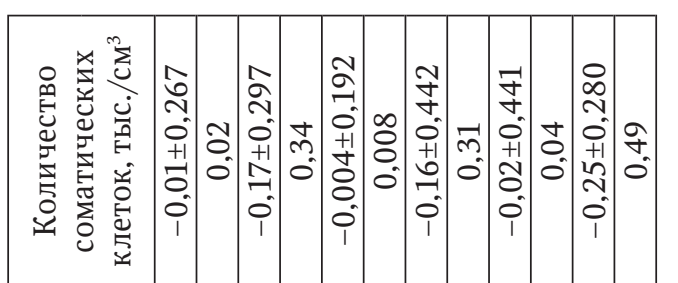

на содержание жира в молоке дочерей $\left(\eta^{2}=13,9\right.$; $P>0,99)$. Возраст (в лактациях) дочерей достоверно повлиял на суточный удой, содержание в молоке сухого вещества, СОМО и температуру замерзания $\left(\eta^{2}=8,3-11,8 ; P>0,95-0,99\right)$. Полученные результаты могут быть использованы в селекционном процессе для повышения качества молока при разведении коров красно-пестрой породы.

\section{СПИСОК ЛИТЕРАТУРЫ}

1. Авдеенко А.В., Авдеенко В.С., Молчанов А.В. Воспроизводство и качество молока коров симментальской и черно-пестрой пород // Аграрный научный журнал. - 2014. - № 10. - С. 3-5.

2. Быданщева Е.Н., Кавардакова О.Ю. Влияние уровня молочной продуктивности матерей на продолжительность хозяйственного использования коров // Известия Оренбургского государственного аграрного университета. - 2012. - № 5 (37). - С. 114-116.

3. Вильвер Д.С. Физико-химические показатели молока коров в зависимости от возраста матерей // Молочное и мясное скотоводство. - 2012. - № 2. C. 30-31.

4. Вильвер Д.С. Влияние генотипических факторов на хозяйственно полезные признаки коров первого отела // Научно-методический электронный журнал «Концепт». - 2015. - Т. 13. - С. 2051-2055.

5. Вильвер М.С., Фомина Н.В. Естественная резистентность коров-матерей и их дочерей в стаде ООО «Деметра» Челябинской области // Известия Оренбургского государственного аграрного университета. - 2014. - № 1 (45). - С. 96-97.

6. Ерофеев В.И., Андреев А.И., Шолин С.Ю. Влияние генотипа животных на молочную продуктивность и качество молока коров // Вестник Ульяновской государственной сельскохозяйственной академии. 2018. - № 3 (43). - C. 122-125.

7. Кулешова Е.А., Бондаренко М.В. Влияние материнской наследственности на устойчивость коров к маститу // Сборник научных трудов Краснодарского научного центра по зоотехнии и ветеринарии. - 2018. - Т. 7. № 2. - C. 27-32.

8. Титова С.В. Влияние матерей на продуктивное долголетие коров // Вестник Марийского государственного университета. - 2018. - Т. 4. - № 3. C. $63-68$.

9. Чеченихина О.С. Реализация генетического потенциала молочной продуктивности коров // Вестник Алтайского государственного аграрного университета. - 2011. - № 9 (83). - С. 59-62.

10. Шайдуллин Р.Р., Шарафутдинов Г.С., Сибагатуллин Ф.С. Степень влияния родителей на продуктивность коров дочерей // Научно-методический электронный журнал «Концепт». - 2013. - Т. 3. C. 536-540.

11. Щербатый 3.Е., Боднар П.В. Зависимость молочной продуктивности коров украинской черно-пестрой молочной породы от продуктивности их матерей // Ученые записки УО ВГАВМ. - 2015. - Т. 51. - Вып. 1. Ч. 2. - С. 132-136.

12. Berry D.P., Lonergan P., Butler S.T., Cromie A.R., Fair T., Mossa F., Evans A.C.O. Negative influence of high maternal milk production before and after conception on

\begin{tabular}{|c|c|c|c|c|c|c|}
\hline 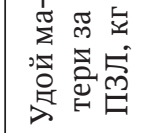 & 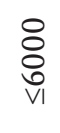 & $\begin{array}{l}\text { ¿े } \\
\text { 잇 }\end{array}$ & 总 & $\begin{array}{l}\text { Oे } \\
\text { o } \\
\text { Vi }\end{array}$ & $\begin{array}{l}8 \\
\text { ¿ } \\
\text { ᄉ }\end{array}$ & 号 \\
\hline 曰吕 & & 7 & & & & \\
\hline
\end{tabular}


Сила влияния $\eta^{2}$ изучаемых факторов на суточный удой и физико-химические свойства молока коров

\begin{tabular}{|c|c|c|c|c|c|c|}
\hline \multirow{3}{*}{ Признак } & \multicolumn{4}{|c|}{ Фактор } & \multirow{2}{*}{\multicolumn{2}{|c|}{$\begin{array}{c}\text { Совместное действие } \\
\text { факторов }\end{array}$}} \\
\hline & \multicolumn{2}{|c|}{$\begin{array}{c}\text { 1-й (возраст дочерей в } \\
\text { лактациях) }\end{array}$} & \multicolumn{2}{|c|}{$\begin{array}{l}\text { 2-й (уровень удоя } \\
\text { матерей) }\end{array}$} & & \\
\hline & $\eta^{2}, \%$ & $\mathrm{~F}$ & $\eta^{2}, \%$ & $\mathrm{~F}$ & $\eta^{2}, \%$ & $\mathrm{~F}$ \\
\hline Суточный удой, \% & 10,1 & $4,53^{* *}$ & 0,3 & 0,14 & 2,7 & 1,19 \\
\hline Массовая доля, \%: жира & 2,4 & 1,16 & 13,9 & $6,59^{* *}$ & 1,3 & 0,64 \\
\hline белка & 1,3 & 0,60 & 0,9 & 0,40 & 4,4 & 2,00 \\
\hline лактозы & 3,0 & 1,40 & 4,2 & 2,00 & 3,4 & 1,60 \\
\hline сухого вещества & 8,3 & $3,84^{*}$ & 3,3 & 1,51 & 4,6 & 2,13 \\
\hline COMO & 8,7 & $4,20^{*}$ & 4,3 & 2,05 & 5,2 & 2,50 \\
\hline Мочевина, мг/100 мл & 2,9 & 1,20 & 0,0 & 0,01 & 3,4 & 1,42 \\
\hline Температура замерзания, ${ }^{\circ} \mathrm{C}$ & 11,8 & $5,42^{* *}$ & 0,0 & 0,00 & 3,2 & 1,47 \\
\hline $\begin{array}{l}\text { Количество соматических клеток, } \\
\text { тыс. } / \text { см³ }^{3}\end{array}$ & 0,3 & 0,13 & 0,2 & 0,10 & 4,7 & 1,94 \\
\hline
\end{tabular}

offspring survival and milk production in dairy cattle author links open overlay panel // Journal of Dairy Science, 2008, Vol. 91, Iss.1, P. 329-337.

13. Fuerst-Waltl B., Reichl A., Fuerst C., Baumung R., Solkner J. Effect of maternal age on milk production traits, fertility, and longevity in cattle // Journal of Dairy Science, 2004, Vol. 87, Iss.7, P. 2293-2298.

Работа выполнена при финансовой поддержке Министерства науки и высшего образования России, номер государственного учета НИОКТР: АААА-А19-119012290066-7.

Ефимова Любовь Валентиновна, канд. с.-x. наук, доиент, ведущий научный сотрудник отдела разведения сельскохозяйственных животных, Красноярский научно-исследовательский институт животноводства - обособленное подразделение ФИЦ КНЦ СО РАН. Россия.

Зазнобина Татьяна Вячеславовна, научный сотрудник отдела разведения сельскохозяйственных животных, Красноярский научно-исследовательский институт животноводства - обособленное подразделение ФИЦ КНЦ СО РАН. Россия.

Фролова Ольга Анатольевна, младший научный сотрудник отдела разведения сельскохозяйственных животных, Красноярский научно-исследовательский институт животноводства - обособленное подразделение ФИЦ КНЦ СО РАН. Россия.

Овчаренко Андрей Станиславович, младший научный сотрудник отдела разведения сельскохозяйственных животных, Красноярский научно-исследовательский институт животноводства - обособленное подразделение ФИЦ КНЦ СО РАН. Россия.

Иванова Ольга Валерьевна, $\partial-p$ c.- $x$. наук, проф. РАН, директор, Красноярский научно-исследовательский институт животноводства - обособленное подразделение ФИЦ КНЦ СО РАН. Россия.

660049, г. Красноярск, просп. Мира, 66.

Тел.: (391) 227-15-89; e-mail: krasniptig75@yandex.ru.

Ключевые слова: корова-мать; корова-дочь; красно-пестрая порода; молоко; физико-химические свойства молока; корреляция; наследуемость; сила влияния.

\section{THE EFFECT OF COWS-MOTHERS ON THE PHYSICOCHEMICAL PROPERTIES OF DAUGHTERS' MILK}

Efimova Lyubov Valentinovna, Candidate of Agricultural Sciences, Associate Profes-sor, Leading Researcher, Krasnoyarsk Research Institute of Animal Husbandry - the Sepa-rate division of the Krasnoyarsk Science Centre of the Siberian Branch of Russian Academy of Science. Russia.

Zaznobina Tatyana Vyacheslavovna, Researcher, Krasnoyarsk Research Institute of Animal Husbandry - the Separate division of the Krasnoyarsk Science Centre of the Sibe-rian Branch of Russian Academy of Science. Russia.

Frolova Olga Anatolyevna, Junior Researcher, Krasnoyarsk Research Institute of An-imal Husbandry - the Separate division of the Krasnoyarsk Science Centre of the Siberian Branch of Russian Academy of Science. Russia.

Ovcharenko Andrey Stanislavovich, Junior Researcher, Krasnoyarsk Research Institute of Animal Husbandry - the Separate division of the Krasnoyarsk Science Centre of the Si-berian Branch of Russian Academy of Science. Russia.

Ivanova Olga Valeryevna, Doctor of Agricultural sciences, Professor of the RAS, Di-rector, Krasnoyarsk Research Institute of Animal Husbandry - the Separate division of the Krasnoyarsk Science Centre of the Siberian Branch of Russian Academy of Science. Russia.

Keywords: cows-mothers; cows-daughters; Red-Motley; milk; physicochemical properties of milk; correlation; heritability; power of influence.
The paper has presented the results of the level productivity mothers' influence on the daily milk yield and physicochemical properties of daughters' milk. The interrelation and heritability of signs, as well as the strength of the influence of two factors (age of daughters-cows in lactations and the milk yield level of mothers) on the component compo-sition and physical properties of milk of cows-daughters, were determined. The studies were carried out in Arefyevskoye JSC of the Krasnoyarsk Territory on Red-Motley cows (43 mother-daughter pairs). It was found the milk of cowsmothers, in comparison with the milk of daughters, was distinguished by better physicochemical properties. The superiority of daughters over mothers in terms of daily milk yield (second lactation) and lactose (first lactation) (by $13.4 \mathrm{~kg}$ and $0.21 \% ; P>0.95$ and $P>0.999)$ was reliable. A positive strong re-lationship was found between the content of dry matter and fat ( $r=0.71$ and 0.79) in the milk of mothers and daughters. A significant effect of mothers on the fat content in their daughters' milk $\left(\eta^{2}=13.9 ; P>0.99\right)$ was revealed. The age of daughters in lactations reliably influenced on their daily milk yield, the content of dry matter in milk, solid-not-fat (SNF) and freezing temperature of milk $\left(\eta^{2}=\right.$ 8.3-11.8; P $>$ 0.95-0.99). 